\title{
Assessment of drug information skills and resources utilisation among pharmacy students: A cross-sectional study
}

\author{
Sarah Al Hussain ${ }^{1}(\mathbb{D})$, Ahmad Sarsour ${ }^{1,2}$ (D), Mohammad Zaitoun ${ }^{1,3}$ (D) \\ ${ }^{1}$ Pharmacy Practice Department, College of Clinical Pharmacy, King Faisal University, Al-Ahsa, Saudi Arabia \\ 2 Pharmacy Department, Regency hospital, Sylvania, Ohio, United States \\ 3 Pharmaceutical Care Administration, Armed forces hospitals southern region, Khamis Mushait, Saudi Arabia
}

\section{Keywords}

Advanced Pharmacy Practice Experience

(APPE)

Curriculum development

Drug information

Evidence-based practice (EBP)

Pharmacy student

\section{Correspondence}

Mohammad Zaitoun

Pharmacy Practice Department

College of Clinical Pharmacy

King Faisal University

Al-Ahsa

Saudi Arabia

mzaitoun84@gmail.com

\begin{abstract}
Objective: To identify drug information (DI) resources commonly used by pharmacy students of King Faisal University, Saudi Arabia, and to assess their ability to determine the appropriate ones for different clinical situations. Methods: A cross-sectional study was conducted in April 2014 ( $n=92$ ). A paper-based questionnaire was developed, validated, and administered to fifth-year Pharm.D. students and advanced pharmacy practice experience (APPE) interns. It investigated the students' DI sources preferences. Besides, it evaluated their competency in classifying DI resources and identifying the best resource to answer case-based multiple-choice questions. Moreover, the study aimed at assessing the impact of providing a case-based combined module of evidence-based practice (EBP) and DI for fifth-year students (new study plan) compared to delivering separate EBP and DI modules through theoretical lectures (old study plan-APPE interns). Results: The preferred resources to the students were online recourses $(85.86 \%)$, soft copy books $(26.08 \%)$, and mobile applications (25\%). For the DI mobile applications, Medscape was the most common (63.4\%), followed by Micromedex (53.5\%), Lexicomp (42.3\%), and Dynamed (16.9\%). Fifthyear students' scores were significantly higher than APPE interns for the case-based questions. Students' GPAs were moderately correlated with their total scores. Conclusion: Study participants preferred using electronic DI resources to printed ones. The combined EBP-DI course could be a better option as it links the DI knowledge to clinical situations.
\end{abstract}

\section{Introduction}

Drug information provision to healthcare professionals, patients, and the general public is one of the leading pharmacists' roles. For effective pharmaceutical service, pharmacists must be able to locate the most updated and reliable drug information using appropriate resources (World Health Organization, 1994; Nathan, 2013; Ghaibi et al., 2015; Toklu, 2015). Thus, pharmacy students should have a good knowledge of the different categories of drug information resources and develop drug information skills to become competent in this aspect. According to previous studies, drug information services have a positive impact on clinical outcomes (Cardoni \&
Thompson, 1978; Melnyk et al., 2000; Hedegaard \& Damkier, 2009; Bramley et al., 2013; Strobach et al., 2015), were associated with cost and practitioner hours savings (Kinky et al., 1999; Marrone \& Heck, 2000), and were highly valued by other healthcare professionals (Hedegaard \& Damkier, 2009; McEntee et al., 2010).

For the Pharm.D. programme of the college of clinical pharmacy, King Faisal University, an ACPE certified and CCAPP accredited programme, the old study plan had separated drug information services (DI) and evidencebased practice (EBP) modules. At that time, these modules were delivered as theoretical lectures without practical classes in the fourth and fifth years. Students were taught how to formulate answerable clinical 
questions, search and review information, critically appraise, and employ the results in clinical practice. The drug information services course covers the pharmacists' activities in providing drug information, including a systematic approach to answering drug information inquiries, drug information resources, evaluation of medical websites and literature, and drug use evaluation. Based on the instructor of these modules recommendations, the new study plan incorporated both drug information services and EBP into one module and contained practical cases to develop students' DI skills. After the fifth year, students have their advanced pharmacy practice experience (APPE) year.

To the authors' knowledge, no previous studies have investigated either the Saudi pharmacy students' DI sources preferences or their DI knowledge and skills. Therefore, this study was conducted to meet this objective and examine the impact of study plan modification.

\section{Methods}

A cross-sectional study was conducted in April 2014. For data collection purposes, an English paper-based questionnaire was developed. It consisted of three sections: the first section documented participants' demographics; the second section aimed at identifying the most commonly used DI resources among students; the third section assessed the study participants' ability to classify different drug information resources correctly (i.e. primary, secondary, or tertiary). Additionally, it tested their competence to identify the most appropriate DI resources for different clinical situations through 11 case-based multiple-choice questions. The questionnaire was first validated with ten students; Cronbach's alpha was calculated based on their responses to confirm the internal consistency of the questionnaire and whether there were any modifications needed. The survey was then distributed to fifth-year Pharm.D. students who took the combined module and APPE pharmacy students who took the separate modules at King Faisal University in Al-Ahsa, Saudi Arabia. Both student groups were assessed through a paper-based evaluation. Informed consent was obtained from the participants after explaining the aim of the study. The study was approved by the scientific research committee at King Faisal University.

Responses were coded and entered into SPSS version 21. For the descriptive data, numbers and percentages for each variable were calculated. The scores were tested for normality using the Shapiro-Wilk test. Based on its results, parametric tests were selected to compare the mean scores of the two groups and investigate whether the scores were correlated with students' GPAs or not. The correlation coefficient value was interpreted according to the following scale: $r=0$ $0.3=$ no correlation, $r>0.3$ to $0.5=$ weak correlation, $r>0.5$ to $0.7=$ moderate correlation, $r>0.7$ to $1=$ strong correlation. A $p$-value of less than 0.05 was considered significant.

\section{Results}

Based on the first ten responses, Cronbach's alpha was 0.79 , and there was no need for modifications in the questionnaire. All fifth-year and APPE interns participated in the study $(n=92)$. The students were invigilated during questionnaire completion. Table I presents the demographics of the study participants.

Table I: Study participants' demographics

\begin{tabular}{lccc}
\hline & $\begin{array}{c}\text { Fifth year } \\
\text { students } \\
\mathbf{n = 4 5}\end{array}$ & $\begin{array}{c}\text { APPE } \\
\text { interns } \\
\mathbf{n}=\mathbf{4 7}\end{array}$ & $\begin{array}{c}\text { All study } \\
\text { participants } \\
\mathbf{n}=\mathbf{9 2}\end{array}$ \\
\hline Age (mean \pm SD) & $22.86 \pm 0.6$ & $23.7 \pm 0.65$ & $23.3 \pm 0.75$ \\
Male gender, $\mathrm{n}(\%)$ & $21(46.67)$ & $25(53.19)$ & $46(50)$ \\
GPA, median (range) & $\mathrm{C}(\mathrm{A}-\mathrm{D})$ & $\mathrm{B}(\mathrm{A}-\mathrm{D})$ & $\mathrm{B}(\mathrm{A}-\mathrm{D})$ \\
$\mathrm{A}, \mathrm{n}(\%)$ & $5(11.11)$ & $8(17.02)$ & $13(14.13)$ \\
$\mathrm{B}, \mathrm{n}(\%)$ & $12(26.67)$ & $21(44.68)$ & $33(35.87)$ \\
$\mathrm{C}, \mathrm{n}(\%)$ & $25(55.56)$ & $15(31.91)$ & $40(43.48)$ \\
$\mathrm{D}, \mathrm{n}(\%)$ & $3(6.67)$ & $3(6.38)$ & $6(6.52)$ \\
\hline
\end{tabular}

The most preferred drug information resources among fifth-year and APPE pharmacy students were online resources, whereas hard-copy books and leaflets were less frequently used (Table II).

Table II: Classification of the most preferred drug information resources

\begin{tabular}{|c|c|c|c|}
\hline References & $\begin{array}{c}\text { Fifth year } \\
\text { students } \\
n=45\end{array}$ & $\begin{array}{c}\text { APPE } \\
\text { interns } \\
n=47\end{array}$ & $\begin{array}{c}\text { All study } \\
\text { participants } \\
\text { n=92 }\end{array}$ \\
\hline $\begin{array}{l}\text { Online resources, } \\
\mathrm{n}(\%)\end{array}$ & $41(91.11)$ & $38(80.85)$ & 79 (85.86) \\
\hline $\begin{array}{l}\text { Books (Soft copy), } \\
\text { n (\%) }\end{array}$ & $15(33.33)$ & $9(19.14)$ & $24(26.08)$ \\
\hline $\begin{array}{l}\text { Mobile applications, } \\
\text { n (\%) }\end{array}$ & $16(35.56)$ & 7 (14.89) & $23(25)$ \\
\hline $\begin{array}{l}\text { Books (Hard copy), } \\
\text { n (\%) }\end{array}$ & $3(6.67)$ & $2(4.25)$ & $5(5.43)$ \\
\hline Leaflets, n (\%) & $2(4.44)$ & $0(0)$ & $2(2.17)$ \\
\hline
\end{tabular}


For DI mobile applications, 71 students reported using them $(77.2 \%, 35$ of the fifth-year students, and 36 of the APPE interns). The most commonly used DI mobile applications were Medscape, followed by Micromedex, Lexicomp, and Dynamed (Table III). As for classifying DI resources and answering the case-based questions, the fifth-year students scored higher in both sub-sections but reached statistical significance in only the casebased items (6.42 vs 6.09, $p=.046$ ).

Table III: The usage pattern of drug information mobile applications

\begin{tabular}{lccc}
\hline Mobile applications & $\begin{array}{c}\text { Fifth year } \\
\text { students }\end{array}$ & $\begin{array}{c}\text { APPE } \\
\text { interns }\end{array}$ & $\begin{array}{c}\text { Total } \\
\text { (\%) }\end{array}$ \\
\hline Medscape & 30 & 15 & $45(63.4)$ \\
Micromedex & 20 & 18 & $38(53.5)$ \\
Lexicomp & - & 30 & $30(42.3)$ \\
Dynamed & - & 10 & $12(16.9)$ \\
Epocrates & 4 & 2 & $6(8.5)$ \\
Skyscape & 1 & 2 & $3(4.2)$ \\
Uptodate & - & 2 & $2(2.8)$ \\
Sanford & - & 2 & $2(2.8)$ \\
Webmd & 1 & 1 & $2(2.8)$ \\
Drugs.com & 1 & - & $1(1.4)$ \\
Dialysis of drugs & - & 1 & $1(1.4)$ \\
Drugdz & - & $1(1.4)$ \\
\hline
\end{tabular}

Tables IV and $\mathrm{V}$ show the percentages of correct answers for each assessment question.

Table IV: Participants' ability to classify drug information sources

\begin{tabular}{lccc}
\hline $\begin{array}{l}\text { Drug } \\
\text { information } \\
\text { resources }\end{array}$ & $\begin{array}{c}\text { Fifth-year } \\
\text { students } \\
\mathbf{n = 4 5}\end{array}$ & $\begin{array}{c}\text { APPE } \\
\text { interns } \\
\mathbf{n = 4 7}\end{array}$ & $\begin{array}{c}\text { All study } \\
\text { participants } \\
\mathbf{n}=92\end{array}$ \\
\hline $\begin{array}{l}\text { Textbooks } \\
\text { Clinical study }\end{array}$ & $35(77.78)$ & $41(87.23)$ & $76(82.6)$ \\
$\begin{array}{l}\text { articles } \\
\text { Saudi National } \\
\text { Formulary }\end{array}$ & $32(71.11)$ & $22(46.8)$ & $54(78.3)$ \\
$\begin{array}{l}\text { Internet } \\
\text { websites }\end{array}$ & $24(53.33)$ & $26(55.31)$ & $50(54.35)$ \\
$\begin{array}{l}\text { Drug } \\
\text { monograph } \\
\text { databases }\end{array}$ & $25(55.56)$ & $24(51.06)$ & $49(53.26)$ \\
$\begin{array}{l}\text { PubMed } \\
\text { Package inserts }\end{array}$ & $19(42.22)$ & $16(34.04)$ & $35(38.04)$ \\
\hline
\end{tabular}

Despite scoring higher in both sub-sections, the difference between the means of the total score of the two study groups did not reach the level of statistical significance (10.71 for fifth-year students vs 10.06 for APPE interns, $p=0.164)$. A moderate positive correlation was found between participants' GPAs and their total scores $(r=0.55, p<0.001)$.

Table V: Participants' ability to select appropriate drug information sources

\begin{tabular}{|c|c|c|c|}
\hline $\begin{array}{l}\text { Question } \\
\text { category }\end{array}$ & $\begin{array}{c}\begin{array}{c}\text { Fifth- } \\
\text { year } \\
\text { students } \\
n=45 \\
R\end{array}\end{array}$ & $\begin{array}{c}\text { APPE } \\
\text { interns } \\
n=47 \\
\text { ht answers }\end{array}$ & 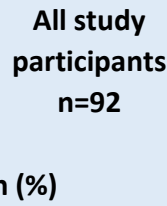 \\
\hline Drug interactions & $38(84.44)$ & $39(82.97)$ & 77 (83.7) \\
\hline $\begin{array}{l}\text { Drug availability in } \\
\text { market }\end{array}$ & $35(77.78)$ & $36(76.59)$ & 71 (77.17) \\
\hline $\begin{array}{l}\text { Drugs in } \\
\text { pregnancy }\end{array}$ & $29(64.44)$ & 36 (76.59) & $65(70.65)$ \\
\hline $\begin{array}{l}\text { Dose adjustment } \\
\text { in renal } \\
\text { impairment }\end{array}$ & $26(57.78)$ & $35(74.46)$ & $61(66.3)$ \\
\hline Searching strategy & $31(68.89)$ & $22(46.8)$ & $53(57.61)$ \\
\hline $\begin{array}{l}\text { Intravenous } \\
\text { medications } \\
\text { compatibility }\end{array}$ & $26(57.78)$ & $27(57.44)$ & $53(57.61)$ \\
\hline $\begin{array}{l}\text { Drug } \\
\text { administration via } \\
\text { enteral feeding }\end{array}$ & $25(55.56)$ & $23(48.93)$ & $48(52.17)$ \\
\hline Adverse reactions & $29(64.44)$ & $15(31.91)$ & $44(47.82)$ \\
\hline Drug off-label uses & $23(51.11)$ & $15(31.91)$ & $38(41.3)$ \\
\hline $\begin{array}{l}\text { Dosing in } \\
\text { neonates }\end{array}$ & $17(37.78)$ & $17(36.17)$ & 34 (36.96) \\
\hline $\begin{array}{l}\text { Formulary } \\
\text { addition }\end{array}$ & $11(24.44)$ & $22(46.8)$ & $33(35.87)$ \\
\hline
\end{tabular}

\section{Discussion}

In this cross-sectional study, Medscape was the most commonly used mobile application among study participants, possibly because it is free. Lexicomp and Dynamed were solely used among the APPE students as the college was officially providing them with access. A study on students and faculty at Wingate University School of Pharmacy in North Carolina, United States, assessed the preferred DI resource and the mechanism of accessing those resources and found that Lexicomp Online was the preferred tertiary resource used (Hanrahan \& Cole, 2014). Another study showed that Micromedex, Drug Facts and Comparisons, and package inserts were the most frequently used references among students trained in community pharmacies (Cerulli et al., 2004). Other studies conducted among community pharmacists found that 
the official Swiss Drug Reference Book and Drug Facts and Comparisons were the most likely utilised resources to answer questions (Zehnder et al., 2004; Lauderdale et al., 2007;). The results of such studies could be affected by the availability of subscriptionservice drug information sources provided by different institutions.

In the present study, fifth-year Pharm.D. students performed statistically better in identifying the best drug information resource for clinical-based questions despite having limited practice experience compared to APPE interns and a lower median GPA. This finding could imply that the combined EBP-DI module could be a more practical option in developing students' DI competencies. A previous study has assessed the benefit of an elective course in evidence-based medicine prior to APPE by evaluating students' performance after completing the course. Pre- and post-test were given to the students to assess the core evidence-based medicine concepts and found an improvement of $83 \%$. Feedback from students and preceptors showed consensus on the benefit of taking an EBP course (Bookstaver et al., 2011). Another study also evaluated students by a survey given to students before and after completing a combined EBP-DI course and found a marked improvement in their ability to utilise drug information resources and develop evidence-based recommendations (Longyhore et al., 2011). Improvements in student skills, knowledge, and confidence were also reported after incorporating active learning strategies into drug information and literature evaluation courses (Timpe et al., 2006). In Japan, a drug information practical training program, which included conducting role-plays, was effective and significantly improved students' interest in direct patient care that cannot be emulated by didactics (Yamamoto et al., 2011).

One approach to improving the DI skills of students is by incorporating DI concepts in all four years of the Doctor of Pharmacy programme, as shown in the curriculum at the University of Southern California (Wood et al., 1990). By implementing this approach, students could have comprehensive knowledge about searching, analysing skills, and professionally providing the requested information. Another recommendation is to implement a drug information rotation supervised by a well-trained preceptor. Although other rotations would include drug information, those preceptors may not be competent, and the time dedicated to improving DI skills would be limited (Bernknopf et al., 2009). This recommendation has been recently implemented in King Faisal University APPE. The current study is a single-centre experience, which could limit the generalisability of its results. However, its findings could be the basis for conducting multicentre comparative studies with larger samples aiming at determining the most practical methodology to deliver DI modules and develop pharmacy students DI knowledge and skills.

\section{Conclusion:}

Study participants preferred using electronic DI resources (websites, soft copy books, and mobile applications) to printed ones. The combined EBP-DI course with practical sessions seems to be a better option than the separate theoretical courses, as it ties in the information of utilising DI resources in clinical scenarios. The curriculum should be routinely evaluated to enhance student DI skills.

\section{Acknowledgements}

The authors are sincerely thankful to all students who participated in this study and King Faisal University for their support. The authors are also grateful to Dr Tahir Khan, PhD, Institute of Pharmaceutical Science, UVAS, for reviewing the data collection tool and pharmacist Nouran Hamza, MS, for the support in statistical analyses.

\section{References:}

Bernknopf, A. C., Karpinski, J. P., McKeever, A. L., Peak, A. S., Smith, K. M., Smith, W. D., Timpe, E. M., \& Ward, K. E. (2009). Drug information: from education to practice. Pharmacotherapy, 29(3), 331-346. https://doi.org/10.1592/phco.29.3.331

Bookstaver, P. B., Rudisill, C. N., Bickley, A. R., McAbee, C., Miller, A. D., Piro, C. C., \& Schulz, R. (2011). An evidencebased medicine elective course to improve student performance in advanced pharmacy practice experiences. Am J Pharm Educ, 75(1), 9. https://doi.org/10.5688/ajpe7519

Bramley, D. M., Innes, A. J., Duggan, C., \& Oborne, C. A. (2013). The impact of Medicines Information enquiry answering on patient care and outcomes. Int J Pharm Pract, 21(6), 393-404. https://doi.org/10.1111/ijpp.12018

Cardoni, A. A., \& Thompson, T. J. (1978). Impact of Drug Information Services on Patient Care. American Journal of Health-System Pharmacy, 35(10), 1233-1237. https://doi.org/10.1093/ajhp/35.10.1233

Cerulli, J., Zeolla, M. M., \& Cottrell, J. (2004). Drug Information Questions Posed to Community Pharmacy Advanced Practice Experience Students. American Journal of Pharmaceutical Education, 68(3), 68. https://doi.org/10.5688/aj680368

Ghaibi, S., Ipema, H., \& Gabay, M. (2015). ASHP Guidelines on the Pharmacist's Role in Providing Drug Information. 
American Journal of Health-System Pharmacy, 72(7), 573 577. https://doi.org/10.2146/sp150002

Hanrahan, C. T., \& Cole, S. W. (2014). Assessment of drug information resource preferences of pharmacy students and faculty. Journal of the Medical Library Association: JMLA, 102(2), 117-121. https://doi.org/10.3163/1536-

5050.102.2.012

Hedegaard, U., \& Damkier, P. (2009). Problem-oriented drug information: physicians' expectations and impact on clinical practice. Eur J Clin Pharmacol, 65(5), 515-522.

https://doi.org/10.1007/s00228-008-0604-5

Kinky, D. E., Erush, S. C., Laskin, M. S., \& Gibson, G. A. (1999). Economic impact of a drug information service. Ann Pharmacother, 33(1), 11-16. https://doi.org/10.1345/aph.18218

Lauderdale, S. A., Kendrach, M. G., \& Kelly Freeman, M. (2007). Preparing Students for Community Pharmacy Practice During a Drug Information Advanced Practice Experience. Am J Pharm Educ, 71(2), 25. https://doi.org/10.5688/aj710225

Longyhore, D., Ference, K., \& Nanstiel, B. (2011). An elective course in information mastery. Am J Pharm Educ, 75(2), 20. https://doi.org/10.5688/ajpe75220

Marrone, C. M., \& Heck, A. M. (2000). Impact of a Drug Information Service: Practitioner Hours Saved. Hospital Pharmacy, 35(10), 1065-1070.

https://doi.org/10.1177/001857870003501018

McEntee, J. E., Henderson, S. L., Rutter, P. M., Rutter, J., \& Davis, H. J. (2010). Utility and value of a medicines information service provided by pharmacists: a survey of health professionals. Int J Pharm Pract, 18(6), 353-361. https://doi.org/10.1111/j.2042-7174.2010.00068.x

Melnyk, P. S., Shevchuk, Y. M., \& Remillard, A. J. (2000). Impact of the dial access drug information service on patient outcome. Ann Pharmacother, 34(5), 585-592. https://doi.org/10.1345/aph.19173

Nathan, J. P. (2013). Drug information--the systematic approach: continuing education article. J Pharm Pract, 26(2), 78-84. https://doi.org/10.1177/0897190012474229

Strobach, D., Gruber, A. C., Möhler, N. C., \& Vetter-Kerkhoff, C. (2015). Clinical impact of the hospital pharmacy drug information service: how does information on drug-drug interaction enquiries translate into clinical decisions? European Journal of Hospital Pharmacy, 22(2), 83-88. https://doi.org/10.1136/ejhpharm-2014-000487

Timpe, E. M., Motl, S. E., \& Eichner, S. F. (2006). Weekly Active-Learning Activities in a Drug Information and Literature Evaluation Course. Am J Pharm Educ, 70(3), 52. https://doi.org/10.5688/aj700352

Toklu, H. Z. (2015). Promoting evidence-based practice in pharmacies. Integr Pharm Res Pract, 4, 127-131. https://doi.org/10.2147/iprp.S70406

Wood, E. H., Morrison, J. L., \& Oppenheimer, P. R. (1990). Drug information skills for pharmacy students: curriculum integration. Bulletin of the Medical Library Association, 78(1), 8-14.
World Health Organization: The role of the pharmacist in the health care system. (1994). Retrieved 13 March from http://apps.who.int/medicinedocs/pdf/h2995e/h2995e.pdf

Yamamoto, T., Yuda, T., Arimoto, A., Sejima, E., Kawahara, Y., Washiyama, A., \& Futagami, K. (2011). Evaluation of a practical training program for drug information services for fifth-year pharmacy students in a hospital. Yakugaku Zasshi, 131(11), 1621-1628.

https://doi.org/10.1248/yakushi.131.1621

Zehnder, S., Beutler, M., Bruppacher, R., Ehrenhofer, T., \& Hersberger, K. E. (2004). Needs and use of drug information sources in community pharmacies: a questionnaire based survey in German-speaking Switzerland. Pharm World Sci, 26(4), 197-202.

https://doi.org/10.1023/B:PHAR.0000035881.17853.e0 